\title{
The View on the Feature Orientation of Online Marketing of Homestay in the Suburbs of Beijing
}

\author{
Xin Yang ${ }^{1, *}$ \\ ${ }^{1}$ Department of Modern Service Management, Beijing Vocational College of Agriculture, Beijing, China \\ *Corresponding author. Email: xinxinla@126.com
}

\begin{abstract}
The paper summarized the online marketing approaches of homestay in the suburbs of Beijing. It mainly includes the following marketing methods through online travel agencies, web portal travel channels, social networking platforms, blogs, searching engines and governments promotion platforms. The article further states that feature orientation was the key factor in the success of online marketing of homestay. Moreover, it explained how to operate on the feature orientation. The conclusion is that feature orientation on homestay marketing should pay attention to connotation construction, highlight cultural taste, distinguish market demand, take advantage of geographical advantages and prevent commercial erosion. What's more, homestay operators must be good at breakthrough and innovation. Innovation has played a prominent role in improving the leisure agriculture and rural tourism product system, promoting new business standards, and enhancing the brand value of homestays in the Beijing Suburb.
\end{abstract}

Keywords: Homestay, Leisure agriculture, Rural tourism, Online marketing, Feature orientation.

\section{INTRODUCTION}

Homestay tourism in the suburbs of Beijing started in the early 1990s. After more than 30 years of development, it has become a new force in the tourism industry in Beijing, and has also driven new rural construction in the capital and the economic growth of the suburbs of Beijing. With the popularization and application of computer networks, the continuous updating and development of new media such as the Internet and social networking, more and more homestay operators have begun to market their tourism products online. Online marketing has become an important channel and marketing means for the promotion of homestays in the suburbs of Beijing.

\section{ONLINE MARKETING CHANNELS OF HOMESTAYS IN THE SUBURBS OF BEIJING}

The ultimate goal of homestay online marketing is to expand the publicity by means of the Internet's fast dissemination, wide audience and to expand publicity without geographical restrictions, establish awareness, improve website click-through rate and network traffic, collect potential customer information and ultimately achieving effective market development and business performance growth [1]. According to research data, there are currently six major online marketing channels used in the homestays of the suburbs of Beijing.

\subsection{Marketing Through Online Travel Agencies}

Professional online travel agencies usually provide information on tourist attractions, travel guides, dining and other information. Homestay operators use these websites or apps to introduce their homestays, display pictures and other means of marketing. The distinctive feature of this type of website is that it provides visitors with a travelogue. The reader can understand and evaluate the homestays through other people's reviews. The objectivity and authenticity are higher. For example, this type of website includes the Homestay Alliance and the Beijing Suburb Farm Tourism Online. However, the information volume of such websites or apps is particularly large, and the information publishing templates are similar. How to stand out 
in the midst of many homestays is a problem that operators must consider.

\subsection{Marketing Through Web Portal Travel Channels}

Large-scale web portals all have travel channels, such as Sohu Travel, Sina Travel, China Travel, etc. These types of marketing are mainly based on online advertising and community forums, with information publishing and feature recommendation as the main means, the portal's high traffic and high attention have been used to achieve wide-ranging results. In terms of feature recommendation, channel editors will regularly launch special magazines that attract viewers according to seasonal changes, tourist hotspots, etc., such as the weekend tour special edition made by Sohu Travel Channel, special edition of homestays in Beijing suburbs etc., including beautiful essay, pretty pictures and comments. The multi-pronged approach gives the viewer a strong sensory impact and a beautiful emotional experience, which significantly enhances the visibility and brand image of the homestays.

\subsection{Marketing Through Social Networking Platforms}

Social networking marketing is a new channel that has emerged in recent years. It has the advantages of fast information dissemination, targeted customer location, real-time interaction, and easy maintenance of customer resources. It is loved and valued by the younger generation of homestay operators. The Social networking platform is mainly based on user groups such as QQ group, WeChat group, WeChat official accounts and Tik Tok. With the popularization of mobile network terminals such as mobile phones and tablet computers, the marketing space and development prospects are very worthy of attention.

\subsection{Marketing Through Blog Marketing}

Blog marketing is convenient and the entry barrier is low. Homestay operators can use wellknown blog platforms to achieve zero-cost publicity. This approach is favoured by many young and middle-aged operators, and the marketing effect is also ideal. In a blog post, you can attract readers through image and videos, and use topics and keywords to improve search engine rankings. You can also understand customer needs through comments or responses, thereby getting closer to customers. Blog marketing requires meticulous care by homestay operators, a step by step process, showing a more intimate and real connection with readers. At present, the blog platforms commonly used by homestay operators in the Beijing suburbs are Sina blogs and Tencent Weibo.

\subsection{Marketing Through Search Engine Marketing}

Search engine marketing can significantly increase the number of website visits and effectively expand the potential customer base. Although the cost advantage of search engine marketing is obvious compared with traditional marketing methods, it is still a significant expense for the individual homestay operators. The most important thing about search engine marketing is the ranking of homestay information on the search page. At present, the most used by operators is Baidu online sponsored ranking.

\subsection{Marketing Through the Government Promotion Platform}

The government tourism promotion platform usually integrates all-round tourism information such as scenic spots, catering, accommodation, folk customs and special products in the region [2]. The local tourism management department concentrates on promoting local tourism products. The amount of information is large and official, and recommended homestays are more likely to gain the trust of potential customers and consumption is guaranteed. At present, all districts and counties in the suburbs of Beijing have established online tourism promotion platforms. For example, many municipal-level folklore households are recommended by Huairou Tourism Information Network, in addition to introducing homestay characteristics, surrounding scenery, and contact information, also implements a clear price tag and customers can directly book online. For homestay operators, the website also provides membership management to facilitate the processing of their data such as orders. This kind of marketing model, with the help from the government's powerful information platform, propaganda advantages and credibility support, is a good choice for homestay operators.

Through the analysis of the application effects of the above six online marketing channels, we found that it is more beneficial to market tourism 
products in homestays by focusing on several ways of combining different marketing channels, such as government marketing platforms and OTAs, blog and portal website travel channel featured links, WeChat official accounts and blogs through search engine marketing to improve click-through rate, regularly publish theme soft papers and information updates on social platforms, highlighting product features and attracting potential customers.

\section{FEATURE ORIENTATION OF ONLINE MARKETING OF HOMESTAY IN THE SUBURBS OF BEIJING}

Although the effect of online marketing is affected by factors such as the operator's knowledge and skills, experience, cost, time, energy and team support, we found that the feature orientation of homestay tourism products is the key factor for marketing success. The marketing style is like the management method of folklore households, and feature orientation is the soul of the tourism products of the homestays.

\subsection{Feature Orientation Should Pay Attention to Connotation Construction}

The greatest charm of the homestay tourism lies in the rural view, the beautiful natural scenery, the simple rural feeling, the unique folk activities and the free and expansive time space can make the city tourists relax and enjoy the simple and leisure life. The existing homestay tourism mainly focuses on " eating homestay meals, sleeping in farmhouses, and homestay sightseeing". The homogenization of products is important; tourists also find similarity in the process of selecting options, and the differences are not obvious. At present, Beijing's regional characteristics of the tourism industry in various suburban counties have been clearly defined, requiring rural tourism boards to achieve "one district, one color" in terms of industrial structure and quality. Fangshan District is referred to as "Beijing ZuYuan, leisure resort", Daxing District is known as " Green Sea, Sweet Garden", Tongzhou District is "Waterfront New Town, Ancient Town of Grain Transportation", Changping District is "hot spring resort", Huairou District is "night nostalgia", Pinggu District is "Green leisure valley", Miyun County is "fishing circle" and so on. Such clear regional characteristics have pointed out the direction for the development of the homestay tourism industry. In the process of development and marketing of specific tourism products, government managers and homestay operators must firmly grasp the characteristics of the village, highlight the advantages of individual differences, and carry out connotation building [3]. They need to fully inspect and utilize the resources of the region, discover and explore rural history, folklore, aesthetics and economic value, focusing on the development of popular products such as food, cosmetic beauty, handicrafts, etc., but also try to expand interactive products such as featured art, folk traditions and other peculiar products. For example, "Farming and Zen" in Cherry Valley Village of Mentougou District, "Cottage in isolated realms" of Liulitai Village in Pinggu District, "Great Wall Mural" of Beigou Village in Huairou District, "Red Classic" in Jiaozhuanghu Village of Shunyi District, etc. Their distinctive features have impressed visitors and established a good product image and market reputation.

\subsection{Feature Orientation Should Highlight Cultural Taste}

As an ancient civilization that nurtures Chinese children, farming civilization is a magnificent color in the history of world civilization. Homestay tourism can only be developed and prospered for a long time if it is rooted in the fertile soil of cultural tourism. It is not only necessary to create a cultural atmosphere, but also to highlight cultural taste. Comparing the rural tourism of various countries and regions in the world, the classics reflect the cultural essence of the region. For example, the American farm reflects the western cowboy culture, the European manor reflects the noble life culture, and the Korean homestay reflects the traditional family etiquette [4]. The promotion of cultural taste has greatly stimulated the development of the local tourism industry. Taking the village of Loudixia in Mentougou District as an example, there are 29 households with 689 houses in the village, most of which were built in the late Qing Dynasty, the courtyards are built on the hills, and the heights are segregated, the ancient villages of the Ming Dynasty and the Qing Dynasty residences, the shadow wall, the gatehouse, the slogans of the $50 \mathrm{~s}$ and $60 \mathrm{~s}$, the ancient roads, the ancient temples, etc. all make visitors feel the historical change, just like an old wine. The village is currently a national Alevel scenic spot, a municipal-level civilized structure and a municipal-level folk custom tourism village. In addition to tangible cultural assets such as architecture, the layout of geomantic omen, the history of the village and even the name of the village are also topics that tourists are interested in. 
Clothing and accessories bearing the name of the village "Cuan" are widely loved by Chinese and foreign tourists. The characteristics of internationalization have also been initially revealed.

\subsection{Feature Orientation Should Distinguish Market Demand}

The main source of tourists in the Beijing Suburb homestays is urban residents. According to a survey, the main motives of their outings are the relaxation of mind and body, leisure and entertainment. The location of the tour tends to be natural scenery and farms with special experience projects. The service consumer is concerned with accommodation conditions and special food dishes. In the process of building the homestay's tourism products, it should be in line with the tourism market demand and development expectations as much as possible [5]. Only by carrying out target marketing and guided marketing will it achieve remarkable results. At present, Beijing suburb tourism has been developed from the initial needs of satisfying customers' simple food and lodging needs to more advanced experience, entertainment and cultural needs. Customers are more inclined to participate in farmer experience activities, leisure activities and the experience of rural culture. Guided by this trend, homestay operators can try to introduce an experiential diet, where customers pick their own fruits or vegetables or fish for shrimp fishing, and farmers provide cooking services or cooking instructions; visitors can also participate in the production or design activities of handicrafts, fruit, alcohol, etc., participate in the operation and marketing of eco-agricultural labor and even homestays, and enhance the interaction and participation in tourism activities.

\subsection{Feature Orientation Should Take Advantage of Geographical Advantages}

The scaling of operations for homestays and the development of joint households are inevitable for the development of leisure agriculture and rural tourism. Only when they have a certain scale can they form a human landscape and bring economic benefits. In the scale development, the homestays should actively take advantage of the inherent advantages of local scenic spots, property, geographical location, and a series of support policies provided by the government to form individual characteristics [6]. Taking well-known scenic spots as an example, Shidu in Fangshan District, Yunmeng Mountain in Miyun County, Yanqi Lake and Hongluo Temple in Huairou District have all promoted the tourism development of surrounding villages; taking seasonal fruit picking as an example, the cherry in Changping District, peaches in Pinggu District, apples in Yanqing District and persimmons in Fangshan District have become the iconic fruits for tourists. The local government should also give more support and guidance to folklore households in the planning and implementation of tourism industry, improve infrastructure, provide funds and training, update business concepts, and promote the sound development of leisure agriculture and rural tourism.

\subsection{Feature Orientation Should Prevent Commercial Erosion}

Studies have shown that the localization of rural tourism operators and the employment of labor is the fundamental guarantee for the sustainable development of leisure agriculture and rural tourism. To maintain the rural nature of the homestay, it is important to prevent overcommercialization of tourism products. Foreign operators may have advantages in terms of capital, connections, management, etc., but they do not understand the local characteristics and the local public sentiment, and the tourism products they create are often similar and lack new ideas. For local operators, in the process of developing and constructing homestays, we must also pay attention to environmental protection, pay attention to energy conservation and recycling, and strive to develop an eco-friendly tourism industry.

\section{CONCLUSION}

Taking all in all, feature orientation on homestay marketing should pay attention to connotation construction, highlight cultural taste, distinguish market demand, take advantage of geographical advantages and prevent commercial erosion. What's more, homestay operators must be good at breakthrough and innovation. Taking the integrated development of primary, secondary and tertiary industries in rural areas as the path, all suburban counties in Beijing have developed leisure agriculture and rural tourism with their own characteristics according to local conditions and achieved positive results. Beijing has proposed eight rural tourism state concepts, such as leisure farms, ecological fishing villages, country hotels, 
landscapes, international stations, picking gardens, folk customs, and health mountain bars, and set local standards. In addition, Beijing is developing eco-friendly industries, encouraging the development of eco-tourism, boutique homestay, forest health care, pastoral complex and other emerging business forms. Resource-saving and ecofriendly projects such as mountain homestay, forest oxygen bar, rural memory and other projects will be further implemented to turn "clear water and green mountains" into "gold and silver mountains". Innovation has played a prominent role in improving the leisure agriculture and rural tourism product system, promoting new business standards, and enhancing the brand value of homestays in the Beijing Suburb.

\section{AUTHORS' CONTRIBUTIONS} Xin.

This paper is independently completed by Yang

\section{REFERENCES}

[1] Guo Meirong et al. Research on the Innovation and Development of Beijing Leisure Agriculture under the Internet Environment [J]. Agricultural Modernization Research. 2019, 3: 190

[2] Deng Yu. Analysis on the Development and Planning of the Tourism Industry of the Rural Areas in Beijing [J]. Agricultural Economics \& Technology.2012,23(3):38

[3] Chen Xiaoli. Improving and Upgrading the Rural Tourism through Highlighting Chongqing's Characteristics [J]. ChongQing Administration. 2021,22(03):108

[4] Han Boran. Rural Tourism Economy Industry Optimization and Upgrading Strategy [J]. Social Scientist. 2021,(04):54

[5] Ma Jun, Xie Ting. Marketing Strategy of Rural Homestay Tourism under the Background of "Internet Plus" [J]. Tourism Today. 2021,19(14): 36

[6] Lu Shiyue, Yang Junxin. Research on New Media Marketing of Rural Tourism in Heilongjiang Province [J]. Rural Economy and Science-Technology. 2021,32(07):84 